\title{
Implementing a Big-Data Based C2B E-commerce in Agricultural Industry
}

\author{
Jiacong Zhao ${ }^{1, a^{*}}$ and Tingbin Chen ${ }^{2, b}$ \\ ${ }^{1}$ Dalian Neusoft University of Information, Dalian, China \\ ${ }^{2}$ Dalian Neusoft University of Information, Dalian, China \\ azhaojiacong@neusoft.edu.cn, bchentingbin@neusoft.edu.cn \\ * The Corresponding Author
}

\begin{abstract}
Keywords: Customer-to-business; Agricultural industry; Big-data techniques; Case based reasoning; Preferences calculation

Abstract. Recently, social networks and communication tools expose customer to extensive business information. This situation incurs higher customer requirements and rapidly changing market environments. Big-data and information technologies are introduced in business field for customer requirement analysis and preferences prediction, so as to respond to the rapidly changing business scenarios and achieve sustainable development. $\mathrm{C} 2 \mathrm{~B}$ is the reverse model of the traditional Business-to-Customer e-commerce strategy which enables consumers to name products or services such that the organization can generate the demand collection for a specific good or service. In China, current agricultural businesses are limited to B2C e-commerce which cannot accurately figure out urgent market requirements and predict consumer preferences. This situation cannot reverse farmers' inferior position. With consideration of characteristics of agricultural industry, this project deals with agricultural issues with a conceptual e-commerce model named big-data based Customer-to-Business (BD-C2B). This model types big-data and information strategy perspectives to the farming industry and outputs scientific business perspectives, so as to support efficient and effective decision making processes. BD-C2B integrates continuous stream data, information and analytics with stored data, and to analyze stream data chunk-by-chunk while maintaining the continuity of context for farmers to run smarter, more agile e-business. Case based reasoning (CBR) is introduced in this model for logic predicate and propositional logic, which contributes to the likelihood and preferences calculation of new proposed products or services. Analytic hierarchy process (AHP) algorithm and an intuitionistic fuzzy based framework are introduced for evaluating the performance of this model.
\end{abstract}

\section{Introduction}

Recently, information and big-data technology dramatically advances the e-business market development. Computer technology also boosts the user popularization of social networks and communication tools. Customers are extensively exposed to business related issues in this data and information era. This increasingly competitive business circumstance forces companies to meet rapidly changing customer requirements and market environment. In order to achieve to achieve distinctive advantages and sustainable development, a majority of companies have fully integrated internet technology into operations and strategies. The progress of information technology based strategic paradigms transforms traditional product-oriented business models to service-oriented and customer-oriented paradigms. Customer-to-Business (C2B) [1] model is a kind of recent customer-oriented e-commerce tactic. Act as the reverse process of Business-to-Customer (B2C) tactic, $\mathrm{C} 2 \mathrm{~B}$ is proposed for enabling individual customers to generate their own demands, such as price, goods and services. Currently, it is one of the most productive e-business models in terms of capturing users' dynamically changing requirements and expectations. A series of research demonstrates that, instead of short term transaction performance, $\mathrm{C} 2 \mathrm{~B}$ contributes great to build the long term value of the customer relationship management. A large percentage of $\mathrm{C} 2 \mathrm{~B}$ organizations have eventually be able to integrate their business value chain encompassing suppliers, customer, and distribution channels within an industry or across industries [2]. Big-data technology realizes scale, scope and speed economics [3]. In business brunch, big-data techniques break the traditional technology 
limitation in data collection and analysis. Current proposed big-data based e-business models perform well in product description, customer behavior searching and analysis [4], buyer needs synthesis and integration with diverse industries [7]. These models are generally with benefits like easy to use, cost-saving and low dependency on equipment. Agricultural industry in China current are limited to B2C e-commerce which cannot accurately figure out questions like how to synthesize individual's needs into farming industry consensus, how to calculate customer preferences to specific products and how to predict the market share of a product. With consideration of characteristics of agricultural industry, this project deals with previous mentioned dilemmas with a conceptual e-commerce model named big-data based Customer-to-Business (BD-C2B). This model types big-data and information strategy perspectives to the farming industry and outputs scientific business perspectives, so as to support efficient and effective decision making processes. BD-C2B integrates continuous stream data, information and analytics with stored data, and to analyze stream data chunk-by-chunk while maintaining the continuity of context for farmers to run smarter, more agile e-business.

The rest of this paper is arranged as followings. Related work and theoretical background of this project is depicted in Section 2. Then, the design of BD-C2B is specified in section 3. Section 4 evaluates BD-C2B with formal methodologies and explains related findings. Conclusion is given in Section 5 .

\section{Related Work}

The increasingly significance of customer satisfaction and customer relationship management drives the proposition of C2B in both academic and industry field. Dai (2013) stated that C2B model was customer demand first and enterprise production second. E-commerce has empowered consumers to originate requirements that businesses fulfill. Chen (2013) discussed the working mechanism and characteristics of $\mathrm{C} 2 \mathrm{~B}$ from the side of consumer demand and proved its value in terms of business model innovation. $\mathrm{C} 2 \mathrm{~B}$ has been widely used in e-business field for business progress. Selvarajah proved that as the widely usage of social media, C2B enhances private universities students' enrolment by advertising, promoting and creating attractive message [5]. The intuitionistic fuzzy is introduced in [6] to solve multi decision making problems in C2B model. A multi-agent based buyer collective purchasing model is proposed in [7] matching to consumer-to-business e-commerce. This model focuses on synthesizing individual's preferences into business consensus so as to establish a successful business model.

Current big-data techniques are mature enough to support significant revolution in business field, which gains distinctive business performance through the following four components: information technology as enabler, process as beneficiary, people as user and organization as facilitator $[8,13,14]$. Hadoop [9] is one of the most popular big-data warehouses. This distributed file system not only enjoys reputation in diverse data structures storage, but can link directly with other databases for data analysis and context-specific aggregation. Data and text mining tools like metaMaker and Starfish are widely used in business analysis. Natural Language Processing is proposed for retrieving raw XML data and applying data mining. For example, metaMaker is introduced in B2C model for generating metadata with XML file format so as to gain customer preferences automatically [10]. The model proposed in [11] can be used to integrate data from various sources like government, hospitals, news, Internet and police. Then, applying data mining and text mining to theses collected large data sets to discover valid, novel and potential valuable business patterns. [12] introduces a big-data based model for improving the overall quality and efficiency of healthcare by extracting information from digital diagnosing and treating illnesses records. Similarly, complex data from Internet and related institutions is analyzed and accessed to fight crime more effectively and efficiently. What's more, intelligent tools, such as case based reasoning (CBR), are developed based on mathematical concepts to support logic predicate and propositional logic in e-business. Evaluation methodologies for big-data based model and $\mathrm{C} 2 \mathrm{~B}$ e-commerce are proposed. An intuitionistic fuzzy network based assessment work for the performance evaluation of $\mathrm{C} 2 \mathrm{~B}$ model is proposed in [6]. Percentage calculation, Chi-square testing and correlation calculation algorithms are introduced for big-data based e-business model $[15,16]$. 


\section{Model Design}

In China, traditional business structures in farming put farmers in the inferior position, which should be updated by implementing up-to-date $\mathrm{C} 2 \mathrm{~B}$ e-commerce. The adventures of $\mathrm{C} 2 \mathrm{~B}$ e-commence lies on that it integrates customer collaborative information into the products and services provided by the company. Big-data technology enhances $\mathrm{C} 2 \mathrm{~B}$ with considering of key principles of strategic positioning, which are long-term return on investment, distinctive value chains, uniqueness in the market and continuity of corporate direction. The following of this part depicts this model's design process which is mainly divided into two stages. The first stage develops the $\mathrm{C} 2 \mathrm{~B}$ model matching to cultural industry as a whole. The second step integrates big-data techniques into the proposed $\mathrm{C} 2 \mathrm{~B}$ model so as to figure out this big-data based C2B model.

Firstly, with referencing to the features and characteristics of agricultural industry, the C2B model is detailed as Figure.1. Specifically, this model centralizes farmers of a specific geography location as the supplier. E-business companies should establish tight supply chain relationship with suppliers, distributors and customers, especially to agricultural industry. The supply chain of this model is divided into configuration- and coordination-level. As shown in Figure.1, the configuration-level contains information like vendors, production and procurement, while coordination-level comprises abstract related information like cash flow and information flow. Besides, similar to traditional e-business models, this $\mathrm{C} 2 \mathrm{~B}$ model also contains finance, human resources and marketing these three compulsory departments.

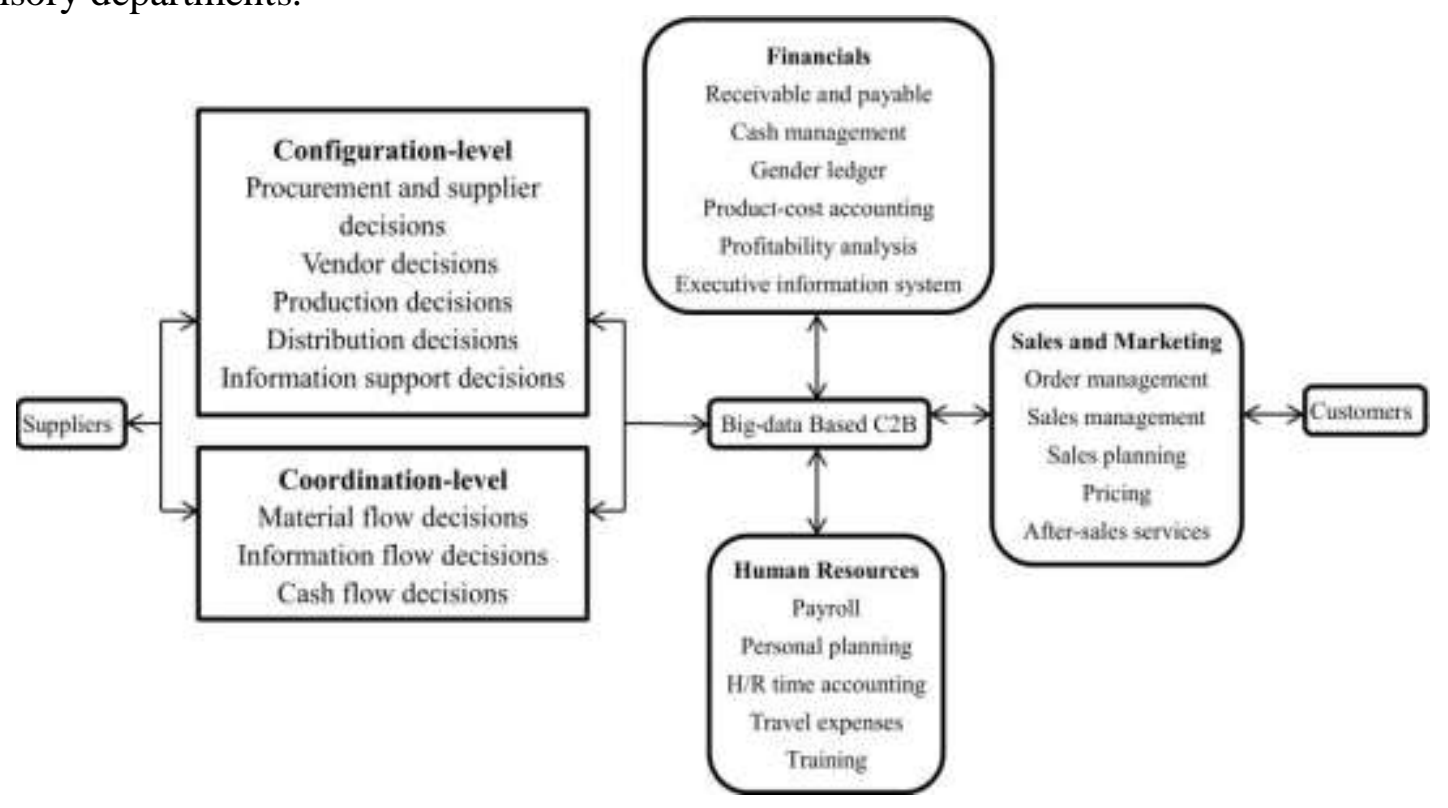

Figure. 1 The Whole C2B Model

The second step integrates big-data technology into the $\mathrm{C} 2 \mathrm{~B}$ models. This model highlights interdependence activities in BD-C2B model where data resources are most likely to have strategic impact. This is why big-data techniques have been applied to information domains ranging from supply chain, customer knowledge and marketing (Figure.2). Specifically, in terms of supply chain domain, information provided by configuration-level is relatively important. This incurs the coordination-level information is taken as one of the data resources for big-data analysis. The process for customer knowledge analysis generally accomplished by the lifecycle shown in Figure.3, which consist stages like product description, buyer needs synthesis and updating. However, this lifecycle does not detail the specific contents that required by customers. In order to overcome this limitation, according to Davenport et al.'s (1998) model for the customer knowledge dimension classification, the customer knowledge of BD-C2B comprises knowledge repositories, knowledge tools, knowledge cultures and knowledge as an asset. Knowledge repositories include internal and external knowledge like competitive intelligence and product oriented marketing material. Knowledge tools emphasize on technologies that provide connectivity, access and transfer to individuals that would like to provide 
related customer knowledge. Knowledge culture means increasing awareness of knowledge in client relationships across national and geographical boundaries. Assets represent intangible value generated by assessments of knowledge. Marketing and sales information is necessary for strategic position, which cannot be neglected in the analysis part. In order to deal with previous mentioned kinds of information, BD-C2B adopts big-data tools for integrating continuous stream data, information and analytics with stored data, and to analyze stream data chunk-by-chunk while maintaining the continuity of context. BD-C2B introduces Hadoop as the database, whose internal structure of is shown in Figure.4.

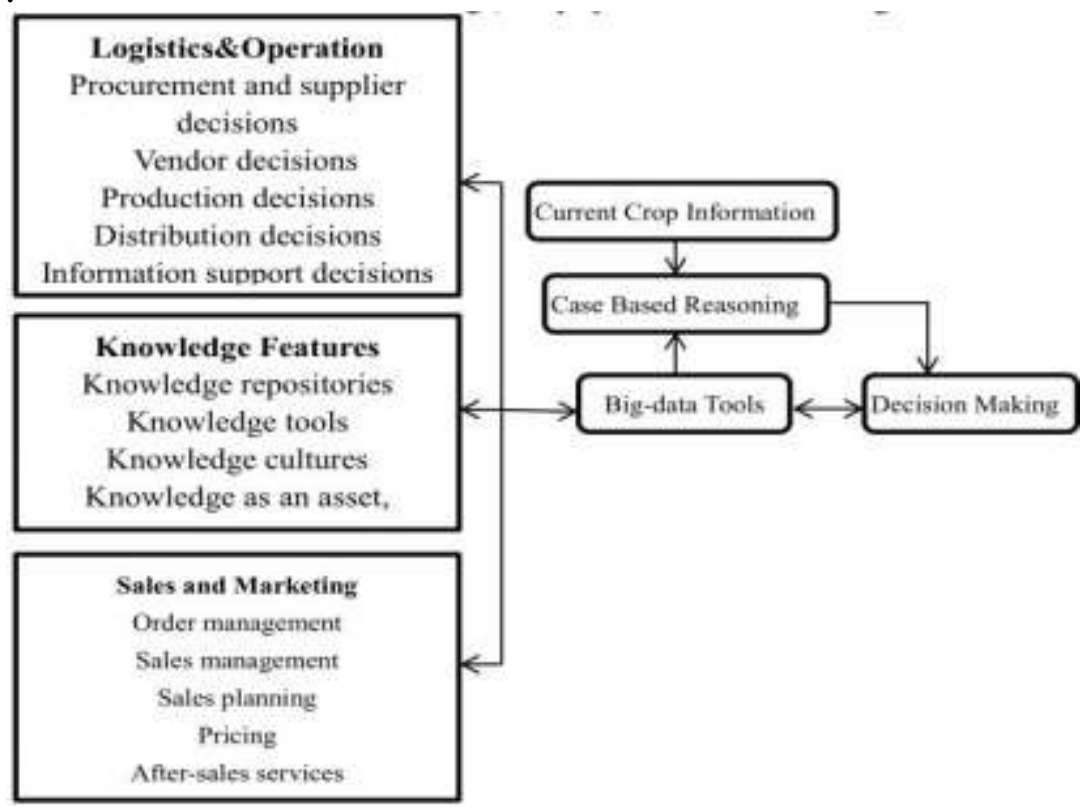

Figure.2 Big-data Integrated C2B Model

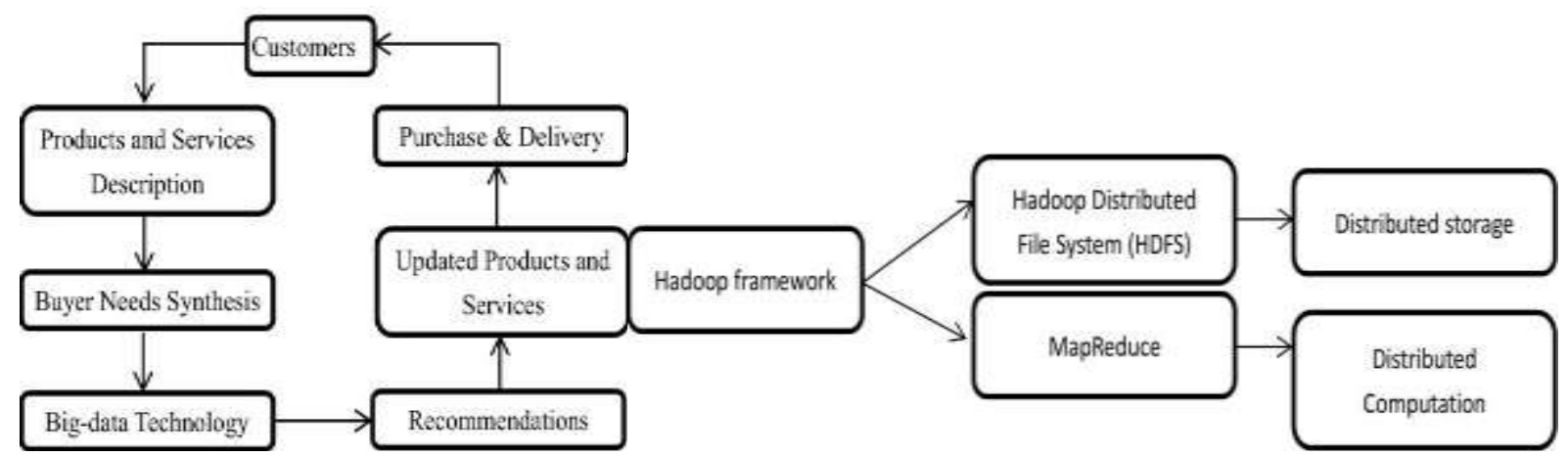

Figure.3 Customer Knowledge Analysis

Figure.4 Hadoop Structure

\section{Model Evaluation}

After briefly reviewing of BD-C2B, herein analytic hierarchy process (AHP) algorithm and an intuitionistic fuzzy based framework are introduced for evaluating this model's performance. AHP has been known to enhance the evaluation and choice in business decision making process. This algorithm is for collecting and synthesizing customers' preferences and then negotiating with the suppliers. AHP evaluates BD-C2B by checking whether it can seek for the best deal from potential suppliers that carry products satisfying a crowd of customers' needs. Additionally, intuitionistic fuzzy framework uses membership and non-membership attributes to support the evaluation of BD-C2B decision making. These attributes are built in intuitionistic fuzzy framework to generate priority weighting vector based on minimum distance and similarity measures. This framework classifies the object type as per customer needs with a ranking for the customer satisfaction.

AHP process establishes the quality priority weights of apples to identify the best suppler. By laying out the priorities of apples with respect to each criterion in a matrix and multiplying each 
column of vectors by the priority of the corresponding criterion and adding across each row results in the quality priorities of the apples as shown in Table.1. The quality priority shows that $\mathrm{C}$ can be chosen as the best suppler. The intuitionistic fuzzy framework of this project avoids problems that arose by individuals' purchasing and analyzing of new ideas and products. This project implements the algorithm that evaluates the performance of a decision making within a group of product. The evaluation process analyzes a crowd of customer requirements and its various attributes, and then comparing customer preferences with all diverse attributes so as to come up with the most appropriate requirement among the listed pool. Initialize all the operating variables to zero, and the result is shown in Table.2. Here, L umin $(a, b, c, d)=(436447,15.06,12.06,4)$ and $L$ amax $(a, b, c, d)=$ $(2790000,22.7,19.7,6)$. Intuitionistic result shows that BD-C2B provides appropriate decision supports in a way that it satisfies all individuals' requirements. Now while predicting the likelihood for customer to buy a specific product some of queries are raised like select a product with shortage distance and with low cost, select a product with a good period of service and higher quality. This result proves that $\mathrm{BD}-\mathrm{C} 2 \mathrm{~B}$ provides appropriate decision making process.

Table 1 Quality priorities to identify the best supplier

\begin{tabular}{cccccccccc}
\hline $\begin{array}{c}\text { Size } \\
\text { of } \\
\text { apple }\end{array}$ & Transportation & Neighborhood $\begin{array}{c}\text { Color } \\
\text { of } \\
\text { apple }\end{array}$ & Tasty & Package & $\begin{array}{c}\text { General } \\
\text { condition }\end{array}$ & Pricing & $\begin{array}{c}\text { Quality } \\
\text { priority }\end{array}$ \\
\hline & 0.173 & 0.053 & 0.187 & 0.018 & 0.031 & 0.036 & 0.167 & 0.333 & \\
A & 0.753 & 0.233 & 0.754 & 0.335 & 0.675 & 0.747 & 0.200 & 0.072 & 0.395 \\
B & 0.182 & 0.055 & 0.064 & 0.333 & 0.101 & 0.061 & 0.403 & 0.650 & 0.342 \\
C & 0.065 & 0.714 & 0.181 & 0.333 & 0.226 & 0.194 & 0.405 & 0.278 & 0.264 \\
\hline
\end{tabular}

Table.2 Intuitionistic Fuzzy Results

\begin{tabular}{cccccccc}
\hline Al. & B.1 & B.2 & B.3 & B.4 & Min & Max & Rank \\
\hline 1 & 2500000 & 15.73 & 12.73 & 4 & 124.9999825 & 124.999503 & 13 \\
2 & 2790060 & 15.17 & 12.06 & 4 & 139.49985 & 139.499478 & 14 \\
3 & 1386010 & 17.2 & 14.3 & 6 & 69.300063 & 69.299588 & 10 \\
4 & 700000 & 22 & 18 & 6 & 35.00029711 & 34.999816 & 4 \\
5 & 600010 & 21 & 17.6 & 4 & 30.00019701 & 29.999716 & 2 \\
6 & 1381003 & 22.6 & 19.6 & 4 & 69.050322 & 69.04987 & 9 \\
7 & 436437 & 17.88 & 14.88 & 4 & 21.822461 & 21.821957 & 1 \\
8 & 765000 & 17 & 13 & 6 & 38.249987 & 38.249515 & 5 \\
9 & 968501 & 21.54 & 18.64 & 4 & 48.425379 & 48.424797 & 7 \\
10 & 2257000 & 17.5 & 14.26 & 6 & 112.850067 & 112.849575 & 12 \\
11 & 916000 & 21.6 & 18.52 & 5 & 45.800274 & 45.799793 & 6 \\
12 & 607160 & 19.51 & 16.63 & 4 & 30.3581765 & 30.3576956 & 3 \\
13 & 1300010 & 21.46 & 18.47 & 5 & 65.0002675 & 64.9997875 & 8 \\
14 & 1540007 & 19.37 & 16.38 & 5 & 77.0001675 & 76.9996835 & 11 \\
\hline
\end{tabular}

\section{Conclusion}

This project proposes a big-data based $\mathrm{C} 2 \mathrm{~B}$ model matching to agricultural industry. This model firstly conducts the big-data analysis of customer knowledge, supply chain information and market making information. This collects and synthesizes customer requirements, marketing requirements and supply chain situation so as to calculate customer preferences based on feature values. At the same time, the big-data analysis also supports the likelihood ratio testing of current products and product 
plans' availability in the future time. Evaluation results show the acceptability and effectivity of this model. This model provides $\mathrm{C} 2 \mathrm{~B}$ companies more opportunities to understand customer requirements and marketing environments, which enables these companies to progress their business and achieve sustainable development. The future work of this project is to put this model into widely usage in agricultural transitions and make the evaluation working mechanism of this model more precisely.

\section{References}

[1] Phan, Dien D. "E-business development for competitive advantages: a case study." Information \& Management 40.6 (2003): 581-590.

[2] Churchill, Neil C., and Virginia L. Lewis. "The five stages of small business growth." Harvard business review 61.3 (1983): 30-50.

[3] Demirkan, Haluk, and Dursun Delen. "Leveraging the capabilities of service-oriented decision support systems: Putting analytics and big data in cloud." Decision Support Systems 55.1 (2013): 412-421.1.

[4] S. Moore, Gartner forecasts global business intelligence market to grow 9.7 percent in 2011, Gartner Research, Sydney, Australia, Feb. 182011

[5] Selvarajah Krishnan *, Norizzati Bahsri, C2B Increase Students Enrolment, Management 2017, 7(1): 29-34

[6] Thirumalai, Chandrasegar, and M. Senthilkumar. "An Assessment Framework of Intuitionistic Fuzzy Network for C2B Decision Making." A A 10 (2016): 1.

[7] Deng-Neng Chen, An agent-based model for consumer-to-business electronic commerce, Expert Systems with Applications 34 (2008) 469-481

[8] T.J. Davenport, Competing on analytics, Harvard Business Review, January 2006.

[9] Chandrasekar, S., et al. "A novel indexing scheme for efficient handling of small files in Hadoop distributed file system." Computer Communication and Informatics (ICCCI), 2013 International Conference on. IEEE, 2013.

[10] S. Marston, Z. Li, S. Bandyopadhyay, J. Zhang, A. Ghalsasi, Cloud computing - the business perspective, Decision Support Systems 51 (2011) 176.189

[11]D. Delen, A. Oztekin, L. Tomak, An analytic approach to better understanding and management of coronary surgeries, Decision Support Systems 52 (2012) 698-705

[12] W. Mougayar, Opening Digital Markets, McGraw-Hill, New York, 1998

[13] A. Benlian, T. Hess, Opportunities and risks of software-as-a-service: findings from a survey of IT executives, Decision Support Systems 52 (2012) 232-246

[14]Zulkernine, Farhana, et al. "Towards cloud-based analytics-as-a-service (AaaS) for big data analytics in the cloud." Big Data (BigData Congress), 2013 IEEE International Congress on. IEEE, 2013.

[15] W.D. Raisch, The e-Marketplace: Strategies for Success in B2B, McGraw-Hill, New York, 2001

[16]E. Turban, J. Lee, M. Warkentin, H. Chung, Electronic Commerce 2002: A Managerial Perspective, Upper Saddle River, Prentice-Hall, Englewood Cliffs, NJ, 2002. 